\title{
Physical training as treatment for Type 2 (non-insulin-dependent) diabetes in elderly men. A feasibility study over 2 years
}

\author{
E. T. Skarfors, T.A. Wegener, H. Lithell and I. Selinus \\ Departments of Geriatrics, Lung Medicine and Clinical Physiology, Uppsala University, Sweden
}

\begin{abstract}
Summary. At a health examination of men approximately 60 years old, 48 were found to have Type 2 (non-insulin-dependent) diabetes. All had been healthy 10 years earlier. The intention was to randomly allocate those with mild diabetes to a training or a control group and study the long-term influence of regular training on the progress of the disease. However, it was found that the majority - 39 of 48 - had other diseases or were on treatment which made regular training difficult and would have complicated the interpretation of the metabolic effects of training. Eight men took part in a physical training programme for up to 2 years. Aerobic capacity, glucose tolerance and serum lipoproteins were measured before and at the end of the training period. Another group of eight men with Type 2 diabetes, of similar weight, age and relative aerobic capacity, who did not undergo the
\end{abstract}

physical training, served as control subjects. The oxygen uptake increased by $16 \%$ in the training group and decreased by $12 \%$ in the control group but no significant changes could be demonstrated in body weight, fasting blood glucose, serum lipoproteins, glucose tolerance or insulin values at a $75-\mathrm{g}$ oral glucose tolerance test between the two groups. Two patients in the training group developed coronary heart disease, two deteriorated metabolically (drug treatment had to be added), and there were two drop-outs. The results cast doubts on the feasibility and efficacy of physical training as a long-term treatment for the majority of Type 2 diabetic patients, who are older than 60 years.

Key words: Type 2 (non-insulin-dependent) diabetes, physical training, middle-age, men.
There is a fairly solid basis for the contention that regular physical exercise will benefit glucose homeostasis in patients suffering from Type 2 (non-insulin-dependent) diabetes and improve the lipoprotein pattern. These effects would reduce the risk for development of coronary heart disease (CHD). Several training studies in patients with Type 2 diabetes have supported this concept but some of them have been short-term modeof-action investigations rather than feasibility studies and performed on selected groups of rather young Type 2 diabetic patients.

The present study was therefore conducted during a 2-year period with the main aim of finding out if a small group of selected diabetic men, almost 60 years of age, were able to carry out regular physical training over a fairly long period, and if so, whether their maximal oxygen uptake increased significantly; and whether such an increase would be accompanied by improved glucose tolerance and lipoprotein metabolism. Another diabetic but sedentary group of men of the same age were used as control subjects.

\section{Subjects and methods}

All male residents in the municipality of Uppsala born between 1920-1924 were invited to attend a health survey carried out in 1970-1973 [1]. Almost 84\% ( $n=2322)$ participated. An intravenous glucose tolerance test was performed in over 1600 of these men, together with other examinations including determinations of serum lipid concentrations, and anthropometric and blood pressure measurements.

Re-examinations began in 1980. By June 1981 Type 2 diabetes had been diagnosed in 48 subjects on the basis of the criteria proposed by the National Diabetes Data Group [2], with the exception that only one glucose tolerance test was performed. All men were non-diabetic at the investigation almost 10 years earlier.

Criteria for exclusion from physical training were the presence of other major diseases and treatments affecting glucose or lipoprotein metabolism. It was found that most diabetic patients had to be excluded on one or more of these grounds. Thus, 14 had hypertension requiring several drugs for control, seven had symptoms or ECG signs of cardiac disease, and 11 had locomotor dysfunction not compatible with calisthenics or jogging. Four were treated with oral hypoglycaemic drugs and three had chronic bronchitis and/or emphysema. Thus, only nine of these men were suitable for the study; eight were willing to take part in training. One patient in the training group took digoxin $(0.25 \mathrm{mg})$ daily, and all the others were either 
Table 1. Characteristics of the training and control groups at the start of the study

\begin{tabular}{|c|c|c|c|c|}
\hline \multirow{2}{*}{$\begin{array}{l}\text { Patients } \\
\text { Age }\end{array}$} & \multicolumn{2}{|c|}{ Training group } & \multicolumn{2}{|c|}{ Control group } \\
\hline & 59.0 & (1.4) & 59.3 & (1.6) \\
\hline $\begin{array}{l}\text { Duration of diabetes } \\
\text { (years) }\end{array}$ & 2.9 & $(2.8)$ & 2.3 & (3.1) \\
\hline BMI $\left(\mathrm{kg} / \mathrm{m}^{2}\right)$ & 25.38 & $(3.15)$ & 25.13 & $(2.58)$ \\
\hline Body weight (kg) & 78.3 & $(14.1)$ & 77.1 & $(8.9)$ \\
\hline B-glucose $0^{\prime}(\mathrm{mmol} / \mathrm{l})$ & 10.0 & $(4.1)$ & 8.5 & (3.4) \\
\hline B-glucose $120^{\prime}(\mathrm{mmol} / \mathrm{l})$ & 16.8 & $(5.7)$ & 15.1 & $(4.5)$ \\
\hline S-insulin $0^{\prime}(\mathrm{mU} / 1)$ & 19.9 & $(15.2)$ & 17.4 & $(11.0)$ \\
\hline S-triglyc $(\mathrm{mmol} / \mathrm{l})$ & 2.47 & $(0.94)$ & 2.72 & $(1.10)$ \\
\hline S-cholesterol $(\mathrm{mmol} / 1)$ & 6.06 & $(0.76)$ & 5.96 & $(0.86)$ \\
\hline S-HDL-chol (mmol/l) & 1.08 & $(0.29)$ & 0.93 & $(0.35)$ \\
\hline $\mathrm{VO}_{2} \max (\mathrm{ml} / \mathrm{min})$ & 2100 & $(267)$ & 2330 & $(172)$ \\
\hline $\begin{array}{l}\text { B-lactate at sub-maxi- } \\
\text { mal test }(\mathrm{mmol} / \mathrm{l})\end{array}$ & 7.2 & $(1.8)$ & 8.2 & $(2.3)$ \\
\hline $\mathbf{W}_{4^{\prime}}(\mathrm{W})$ & 144 & $(17.8)$ & 125 & $(19.0)$ \\
\hline $\mathrm{HR}$ at $\mathrm{W}_{4}$ & 149.4 & $(8.6)$ & 141.4 & $(20.1)$ \\
\hline
\end{tabular}

$\mathrm{BMI}=$ body mass index; $\mathrm{HDL}=$ high density lipoproteins; $\mathrm{VO}_{2} \max =$ maximal oxygen uptake; $\mathrm{HR}=$ heart rate, $\mathrm{W}_{4}=$ maximal load endured for $\geq 4 \mathrm{~min}$. Mean values (SD) are given. There were no significant differences between the groups. All lipid values and all insulin values were corrected by a factor so that the values of the control group were similar before and after two years of training. The values before training of the training group were then corrected by the same factor

Table 2. Aerobic power $\mathrm{VO}_{2} \max (\mathrm{ml} / \mathrm{min})$ before and after 2 years in the training $(n=6)$ and control $(n=8)$ group. Means (SD) are given

\begin{tabular}{llll}
\hline & $\begin{array}{l}\text { Before } \\
\text { 2 years }\end{array}$ & $\begin{array}{l}\text { After } \\
\text { 2 years }\end{array}$ & $\begin{array}{l}\text { Test of changes } \\
\text { within group }\end{array}$ \\
\hline Training group & $2100(267)$ & $2430(300)$ & $\begin{array}{l}p=0.0004 \\
p=0.004\end{array}$ \\
Control group & $2330(172)$ & $2057(306)$ & $p$
\end{tabular}

The two drop-outs were excluded from this analysis. $\mathrm{VO}_{2}$ from a submaximal test at 18 months in one patient who suffered a myocardial infarction after 23 months is included in the 2-year result. The changes within each group were significantly different $(p=0.0001$ in a test of equal changes over time)

drug-free when the training began or stopped medication prior to the start of the training programme.

Random allocation of trainable candidates to a training and a control group was not performed, as it would have meant too small a training group.

The patients were informed about the aims and plan of the study and gave written consent to participate. Eight Type 2 diabetic patients with musculoskeletal problems, asthma on exertion or hypertension served as control subjects. Of these eight patients two were hypertensive and were receiving bloodpressure-lowering treatment, and one of these two was taking oral hypoglycaemic medication. Another control subject was being treated with sulfonylurea and another one with bronchodilators.

\section{Experimental schedule}

All of the patients in the training and control groups had been given dietetic information by a dietician more than 2 months before the start of the training. Six in the training group and four in the control group had received dietetic advice on two occasions or more.
At least two exercise tests with ECG were carried out prior to the study in order to detect any signs of coronary insufficiency and to determine the maximal oxygen uptake $\left(\mathrm{VO}_{2} \max \right)$.

The training group was scheduled for aerobic work up to approximately $75 \%$ of $\mathrm{VO}_{2} \max$ (calculated from $\mathrm{VO}_{2} \max$ - see above) for $45 \mathrm{~min}$ twice weekly, supervised by a physiotherapist, and were encouraged to carry out training sessions of their own on one additional occasion per week. The training programme consisted of jogging, calisthenics and bicycle riding (on a cycle ergometer). The carotid pulse rate measured by palpation during the ergometer cycle pedalling or at the end of a jogging round was used to assess the intensity of aerobic work. The men were also instructed to count their own pulse and encouraged to attain the desired heart rate. One of the authors took part in one training session per week in order to keep good contact with the patients and to be well informed about any complaints, for example musculoskeletal symptoms.

All details of the investigation had been approved by the local ethical committee of the Faculty of Medicine at Uppsala University.

\section{Study plan}

Before the training programme commenced, and 12 and 24 months after its start, the patients in the training and control groups were subjected to the following tests: an oral glucose tolerance test (OGTT) was performed by giving $75 \mathrm{~g}$ of glucose in $300 \mathrm{ml}$ of water. Blood was sampled for analysis of glucose and serum insulin before and $30,60,90$ and $120 \mathrm{~min}$ after the glucose intake. The OGTT and other blood samplings were performed after an overnight fast.

Blood was also sampled on these three occasions for lipoprotein and apolipoprotein assays, the blood pressure was measured after $10 \mathrm{~min}$ of rest in the supine position, and the body weight and height were measured. Body mass index (BMI) was defined as the ratio of weight $(\mathrm{kg})$ to height squared $\left(\mathrm{m}^{2}\right)$. The exercise ECGs (see below) were performed on other occasions. Three, $6,9,15$ and 18 months after the start of training, blood glucose and serum triglyceride, cholesterol and HDL-cholesterol concentrations were measured,

\section{Laboratory methods}

Glucose concentrations in whole blood were determined by the glucose oxidase method, using GOD-Perid from Boehringer-Mannheim GmbH Diagnostica (Mannheim, FRG) and an LKB 7400 photometer. Serum insulin was measured with the Phadebas test method (Pharmacia, Uppsala, Sweden) based on a radioimmunological technique [3]. During the first year of the study triglyceride and cholesterol concentrations in serum and in the isolated lipoprotein fractions were determined by semi-automated methods in a Technicon Autoanalyzer II [4] using a combination of preparative ultracentrifugation [5] and heparinmanganese precipitation [6]. During the second year a phosphotungstate $/ \mathrm{MgCl}_{2}$ precipitation [7] technique was used and cholesterol and triglyceride concentrations analysed in a Multistat III centrifugal analyser using enzymatic techniques (Boehringer Mannheim GmbH Diagnostica, FRG). Despite careful monitoring of the laboratory procedures, these changes might have affected the accuracy of the results for these variables. A correction factor has been used for comparison of some variable values in Tables 1 and 3 .

Maximal aerobic capacity $\left(\mathrm{VO}_{2} \max \right)$ was determined by means of an electromechanically braked ergometer cycle (Monark, Varberg, Sweden) and the concentration of oxygen in expired air on a Beckman OM 14 polarographic oxygen analyser (Beckman Instruments Inc., Schiller Park, IIl, USA). $\mathrm{VO}_{2}$ max was calculated as the oxygen uptake at the highest recorded heart rate and was based on $\mathrm{VO}_{2}$ measured at a submaximal load and using resting heart rate and estimated basal $\mathrm{VO}_{2}$ as baseline values [8]. At least two tests were performed before the start of training or inclusion in the control group.

Capillary blood samples were collected immediately after the maximal and during the submaximal tests for analysis of the bloodlactate concentrations [9]. 


\section{Statistical analysis}

A fixed, two-way crossed analysis of variance model including main factors for group and time points was used to test the hypothesis of no change over time in the training and control groups respectively. The same model was also used to test the hypothesis of equal changes over time in the two groups.

Some missing 24-month values were replaced by values obtained at 18 and 21 months.

\section{Results}

Before training the control group did not differ significantly from the training group in relative and absolute $\mathrm{VO}_{2} \mathrm{max}$ (measured as $\mathrm{ml} \cdot \mathrm{min}^{-1} \cdot \mathrm{kg}$-body weight ${ }^{-1}$ and $\mathrm{ml} / \mathrm{min}$ respectively), BMI, fasting serum insulin, serum lipids, high density lipoprotein (HDL) cholesterol or blood glucose concentrations (Table 1). One patient in the training group had high fasting-blood glucose values. He later proved to have Type 1 (insulindependent) diabetes and was given insulin treatment (see below). The mean maximal heart rate values and blood-lactate concentrations at the maximal test did not differ between the training and control groups before training (160 vs $152 \mathrm{~min}$ and $7.9 \mathrm{vs} 7.3 \mathrm{mmol} / 1 \mathrm{re}-$ spectively). The highest load (watt) that could be endured for at least $4 \min \left(\mathrm{W}_{4}\right)$ was 144 in the training group and 125 in the control group (NS).

\section{Participation in training}

During the first 8 months the mean proportion of training sessions attended (participation rate) was $68 \%$. Two men dropped out after this period, but were tested again at 12 and 24 months. One complained of pain in his knees when jogging (X-rays were normal), and the other claimed prohibitive social reasons.

The participation rate fell during the following period, and the average rate over two years was $53 \%$ (range $24-80 \%$, drop-outs included).

\section{Somatic events during the follow-up period}

One patient suffered a myocardial infarction at 23 months and was not tested after 24 months (all other subjects in both groups were tested on this occasion). His diabetes deteriorated and he was given oral antidiabetic drugs. A second patient had vague chest discomfort during training and did not increase his oxygen uptake during the second year. His exercise ECG at 12 months was compatible with coronary insufficiency (he had had a myocardial infarction in 1975). His diabetes deteriorated and he was given glibenclamide. A third had to interrupt the training for 2 months after a gall bladder operation and later he also had symptoms from achilles tendinitis. His diabetes
Table 3. Metabolic changes in the training and control groups, mean values $(\bar{x})$ and standard deviations (SD)

\begin{tabular}{|c|c|c|c|c|c|c|c|c|}
\hline & \multicolumn{4}{|c|}{ Before training } & \multicolumn{4}{|c|}{ After 2 years } \\
\hline & \multicolumn{2}{|c|}{$\begin{array}{l}\text { Training } \\
\text { group }\end{array}$} & \multicolumn{2}{|c|}{$\begin{array}{l}\text { Control } \\
\text { group }\end{array}$} & \multicolumn{2}{|c|}{$\begin{array}{l}\text { Training } \\
\text { group }\end{array}$} & \multicolumn{2}{|c|}{$\begin{array}{l}\text { Control } \\
\text { group }\end{array}$} \\
\hline & $\bar{x}$ & SD & $\bar{x}$ & $\mathrm{SD}$ & $\bar{x}$ & $\mathrm{SD}$ & $\bar{x}$ & $\mathrm{SD}$ \\
\hline VLDL-TG & 1.86 & 0.81 & 1.80 & 1.10 & 2.02 & 1.48 & 1.80 & 1.18 \\
\hline VLDL-chol & 1.01 & 0.36 & 0.81 & 0.54 & 0.80 & 0.46 & 0.81 & 0.51 \\
\hline LDL-TG & 0.56 & 0.10 & 0.58 & 0.13 & 0.48 & 0.06 & 0.58 & 0.15 \\
\hline LDL-chol & 4.11 & 0.76 & 4.21 & 0.61 & 4.09 & 0.75 & 4.21 & 0.79 \\
\hline HDL-TG & 0.27 & 0.04 & 0.25 & 0.03 & 0.28 & 0.04 & 0.25 & 0.07 \\
\hline HDL-chol & 1.04 & 0.33 & 0.93 & 0.35 & 1.07 & 0.37 & 0.93 & 0.27 \\
\hline S-TG & 2.82 & 0.78 & 2.72 & 1.10 & 2.87 & 1.36 & 2.72 & 1.34 \\
\hline S-chol & 6.09 & 0.88 & 5.96 & 0.86 & 5.81 & 0.79 & 5.96 & 0.92 \\
\hline Apo A-I & 105.5 & 17.8 & 110.6 & 25.9 & 108.8 & 12.4 & 133.4 & 39.6 \\
\hline Apo A-II & 107.7 & 16.2 & 98.8 & 9.0 & 108.2 & 8.8 & 96.3 & 10.1 \\
\hline Apo B & 155.0 & 44.6 & 129.9 & 31.7 & 159.6 & 37.2 & 126.8 & 39.9 \\
\hline B-glucose $0^{\prime}$ & 11.0 & 4.4 & 8.5 & 3.4 & 9.6 & 3.4 & 6.8 & 1.8 \\
\hline B-glucose $120^{\prime}$ & 18.2 & 5.7 & 15.1 & 4.5 & 16.4 & 6.5 & 11.9 & 3.8 \\
\hline S-insulin $0^{\prime}$ & 17.1 & 11.1 & 17.4 & 11.0 & 19.4 & 8.0 & 17.4 & 9.4 \\
\hline S-insulin $120^{\prime}$ & 41.2 & 23.4 & 61.7 & 56.7 & 48.7 & 25.4 & 61.7 & 27.8 \\
\hline
\end{tabular}

The results for the two drop-outs (training group) were excluded from the analysis. Subjects receiving oral antidiabetic drugs are included. No significant differences were found in the test of equal changes over time either when the two drop-outs were included or when they were excluded. All lipid values and all insulin values were corrected by a factor so that the values of the control group were similar before and after two years of training. The values before training of the training group were then corrected by the same factor. Statistical testing (interaction tests) were performed after this correction. $V L D L=$ very low density lipoprotein; $L D L=$ low density lipoprotein; $\mathrm{HDL}=$ high density lipoprotein; $\mathrm{TG}=$ triglyceride; chol = cholesterol; apo = apolipoprotein .

deteriorated and he was given glibenclamide. However, only the two drop-outs definitively stopped taking part in the training sessions.

In the control group three patients had a deterioration of their diabetes so that oral antidiabetic treatment was started.

\section{Metabolic and physiological changes}

There was a wide range of changes in $\mathrm{VO}_{2} \mathrm{max}(\mathrm{ml} /$ $\min$ ) in the training group, from a decrease of $6.6 \%$ in one of the two drop-outs to an increase of $28.6 \%$ in one patient. The average $\mathrm{VO}_{2} \max$ increased by $15.7 \%$ after 2 years $(p<0.03)$; with the two drop-outs excluded, the increase was $19.8 \%(p<0.02$, Table 2$)$. $\mathrm{VO}_{2}$ max in the control group decreased by an average of $11.7 \%(p<0.01)$. Thus the groups differed in their reaction $(p<0.0001)$.

In contrast, there were no significantly different changes in HDL-cholesterol, low density lipoproteins (LDL) cholesterol, very low density lipoproteins (VLDL) triglycerides, apolipoprotein (apo) A-I, apoA-II, apo B, fasting blood glucose or fasting serum insulin, or in blood glucose or serum insulin $120 \mathrm{~min}$ after the start of OGTT (Table 3). This lack of significant changes occurred irrespective of whether the two dropouts were included in, or excluded from, the calculations. 


\section{Discussion}

The finding that only nine out of 48 patients were suitable for physical training was not what we had expected. The number could have been extended to 12 or maybe 13 individuals but only at the cost of having more interference from pharmacological (antihypertensive) treatment on metabolic variables among the study subjects. Randomisation was an objective of the study from the start but could not be achieved due to this lack of eligible subjects.

The appearance or aggravation of coronary heart disease (two subjects in the training group) and deterioration of diabetes (another two subjects) and two dropouts left only two who were free from illness and medication and in whom the effect of 2 years of training could have been evaluated without demur. Despite these drawbacks, an increase in $\mathrm{VO}_{2} \max$ by $20 \%$ (the two drop-outs excluded) could be demonstrated in the training group. This effect of training on oxygen uptake was not accompanied by any beneficial changes in metabolic variables in the training group as compared to the control group.

There are some studies on metabolic effects of training in Type 2 diabetes to support the contention that beneficial effects can be achieved [10-16].

The individuals in these studies were under 55 years of age and the period of training 3 to 6 months, except in one study which lasted for 12 months [12]. The study populations were not representative for Type 2 diabetic patients, the majority of whom (at least in Scandinavia) were more than 60 years old. Those who were under 55 years of age represented scarcely $25 \%$ of all patients with the disease [17]. The motivation of the patients can much more easily be kept on a high level if a study lasts for three months only.

The present study in men of about 60 years of age indicates that physical training is not feasible as treatment of manifest Type 2 diabetes for the majority of the patients. The main reason is the frequent concurrence of other diseases which makes it difficult to exercise so briskly and/or frequently as to improve glucose metabolism. In men about 10 years younger the metabolic alterations after 6 months of regular training were pronounced, the drop-out rate was lower, and the (relative) contraindications were fewer [16]. Furthermore, the absolute improvements in metabolism may be expected to be larger, as the relative and absolute improvements in $\mathrm{VO}_{2} \max$ can be greater. Therefore, patients below 50 years of age with impaired glucose tolerance and positive heredity for Type 2 diabetes seem to form a suitable group for training, which will hopefully prevent development of the disease.

Acknowledgements. This work was supported by the Swedish Medical Research Council (grant No.5446), the Swedish Medical Association, the Osterman Foundation, the Swedish National Association against Heart and Chest Diseases and the Swedish Diabetes Asso- ciation. We are also indebted to the physiotherapists L. Ström and A. Holmstrand, who led the sessions of physical training, and Professor G.Ström of the Department of Clinical Physiology for valuable advice.

\section{References}

1. Hedstrand $H$ (1975) A study of middle-aged men with particular reference to risk factors for cardiovascular disease. Upsala J Med Sci 19 [Suppl.]: 1-61

2. National Diabetes Data Group (1979) Classification and diagnosis of diabetes mellitus and other categories of glucose intolerance. Diabetes 28: 1039-1057

3. Wide L, Axén R, Porath J (1967) Radioimmunosorbent assay of proteins. Chemical couplings of antibodies in insoluble dextran. Immunochemistry 4: 381-386

4. Rush R, Leon L, Turell J (1971) Automated simultaneous cholesterol and triglyceride determination on the Autoanalyzer II instrument. Adv Automat Analy 1: 503-507

5. Havel RJ, Eder HA, Bragdon JH (1955) The determination and chemical composition of ultracentrifugally separated lipoproteins in human serum. J Clin Invest $34: 1345-1353$

6. Burstein M, Samaille J (1960) Sur un dosage rapide du cholestérol lié au alpha- et au bétalipoprotéins du serum. Clin Chim Acta 5: 609

7. Siegler L, Wu WT (1981) Separation of serum high-density lipoprotein for cholesterol determination: ultracentrifugation vs precipitation with sodium phosphotungstate and magnesium chloride. Clin Chem 27: 838-841

8. Åstrand P-O, Rodahl K (1970) Textbook of work physiology. McGraw-Hill, New York

9. Hohorst HJ (1962) Bestimmung mit Lactatdehydrogenase und DPN. In: Bergmeyer (ed) Methoden der enzymatischen Analyse. Verlag Chemie, Weinheim, pp 266-270

10. Koivisto VA, DeFronzo RA (1984) Exercise in the treatment of type II diabetes. Acta Endocrinol [Suppl] 262: 107-111

11. Ruderman NB, Ganda OP, Johansen K (1979) The effect of physical training on glucose tolerance and plasma lipids in maturity-onset diabetes. Diabetes 28 [Suppl 1]: 89-92

12. Saltin B, Lindgärde F, Houston $M$, Hörlin R, Nygaard E, Gad $\mathbf{P}$ (1979) Physical training and glucose tolerance in middle-aged men with chemical diabetes. Diabetes 28 [Suppl 1]: 30-32

13. Reitman JS, Vasquez B, Klimes I, Nagulesparan M (1984) Improvement of glucose homeostasis after exercise training in noninsulin-dependent diabetes. Diabetes Care 7: 434-441

14. Trovati M, Carta Q, Cavalot F, Vitali S, Banaudi S, Lucchina PG, Fiochi F, Emanuelli G, Lenti G (1984) Influence of physical training on blood glucose control, glucose tolerance, insulin secretion and insulin action in non-insulin-dependent diabetic patients. Diabetes Care 7: 416-420

15. Krotkiewski M, Mandroukas $\mathrm{K}$, Holm G, Lithell $\mathrm{H}$, von Schenk H, Björntorp P, Wroblewski Z, Smith U (1982) Physical training in patients with diabetes type II and patients with obesity and impaired glucose tolerance. Muscle morphology and metabolic aspects. In: Physical training in obesity and diabetes muscle morphology, capillarization and physical training. Göteborg. Thesis

16. Lindgärde F, Malmqvist J, Balke B (1983) Physical fitness, insulin secretion and glucose tolerance in healthy males and mild type-2 diabetes. Acta Diabetol Lat 20: 33-40

17. Laakso M, Pyörälä K (1985) Age of onset and type of diabetes. Diabetes Care 8: 114-117

Received: 24 November 1986

and in revised form: 27 October 1987

Dr. Hans Lithell

Department of Geriatrics

Uppsala University

Box 12042

S-750 12 Uppsala

Sweden 